\title{
Late Discovery Caudal Regression Syndrome: A Case Report!
}

\author{
Soumia Arharas*, Isam Azzahiri, Ibtissam Zouita, Dounia Basraoui, Hicham Jalal
}

Mother and Child Radiology Department, Cadi Ayyad University, University Hospital Mohammed VI of Marrakech, Morocco

DOI: $10.36347 /$ sjmcr.2021.v09i02.021

| Received: 27.01.2021 | Accepted: 12.02.2021 | Published: 27.02.2021

*Corresponding author: Soumia Arharas

Abstract

Case Report

Caudal regression syndrome is a rare congenital malformation syndrome characterized by an abnormal development with varying degrees of the sacral and coccygeal vertebrae associated an other malformations: anorectal, vertebral, urogenital and abnormalities of the lower limbs. We report a case type 2 caudal regression syndrome with late onset in a 10 year-old girl followed for neurological bladder, referred to us for lumbar MRI which objectified the absence of the S4, S5 and coccyx vertebrae. Prenatal diagnosis is possible by obstetric ultrasound and fetal MRI, allowing early management and preventing renal failure. The early diagnosis must be in prenatal made by obstetric ultrasound and fetal MRI, or even a postnatal diagnostic make in front of a neurological bladder allowing adequat management and preventing renal failure.

Keywords: Caudal regression syndrome, neurological bladder, sacrococcygeal agenesis.

Copyright $(\mathcal{C} 2021$ The Author(s): This is an open-access article distributed under the terms of the Creative Commons Attribution 4.0 International License (CC BY-NC 4.0) which permits unrestricted use, distribution, and reproduction in any medium for non-commercial use provided the original author and source are credited.

\section{INTRODUCTION}

Caudal regression syndrome is a heterogeneous group of rare congenital caudal abnormalities, affecting the caudal vertebral column, spinal cord, posterior intestine, urogenital system, and lower extremities [1]. Its cause has not yet been precisely established, but its relationship to maternal diabetes is well demonstrated [2]. Its incidence is estimated to be around 1 in 40,000 to 60,000 live births [3]. According to Renshaw's classification, 4 types are distinguished: 1) partial or total unilateral sacral agenesis, 2) symmetrical and bilateral partial sacral agenesis, 3) Total sacral agenesis and ilial articulating withe the lowest lumbar vertebra present, 4) the caudal endplate of the lowest vertebra resting above either fused ilia or iliac amphiarthrosis $[4,5]$. We report a case of type 2 caudal regression syndrome with late descovery in a 10-year-old girl followed for neurological bladder.

\section{Case Report}

10-year-old girl, with a history of a diabetic mother and recurrent urinary tract infections, followed for neurological bladder since the age of one year under urinary antispasmodic; complicated nine years ago by renal failure, for which she underwent a vesicotomy, after improvement and stabilization of renal function and at the request of the patient, she received a Mitrofanoff. The clinical examination and the biological assessment did not reveal any abnormality. The patient was referred to our establishment for a lumbar MRI looking for a lumber spinal stenosis, however she objected the absence of individualization of the S4, S5 sacral vertebrae and the coccyx with a diverticular bladder (Figure-1). The CT scan confirmed these abnormalities without other associated bone malformation (Figure-2), with reduced left kidney size measuring $4.5 \times 1.6 \mathrm{~cm}$ and compensatory nephromgaly of the right kidney on ultrasound (Figure-3). Faced with the combination of these sacral and urinary malformations, the diagnosis of caudal regression syndrome was selected as type 2 according to the Renshaw classification. 
Soumia Arharas et al., Sch J Med Case Rep, Feb, 2021; 9(2): 193-196

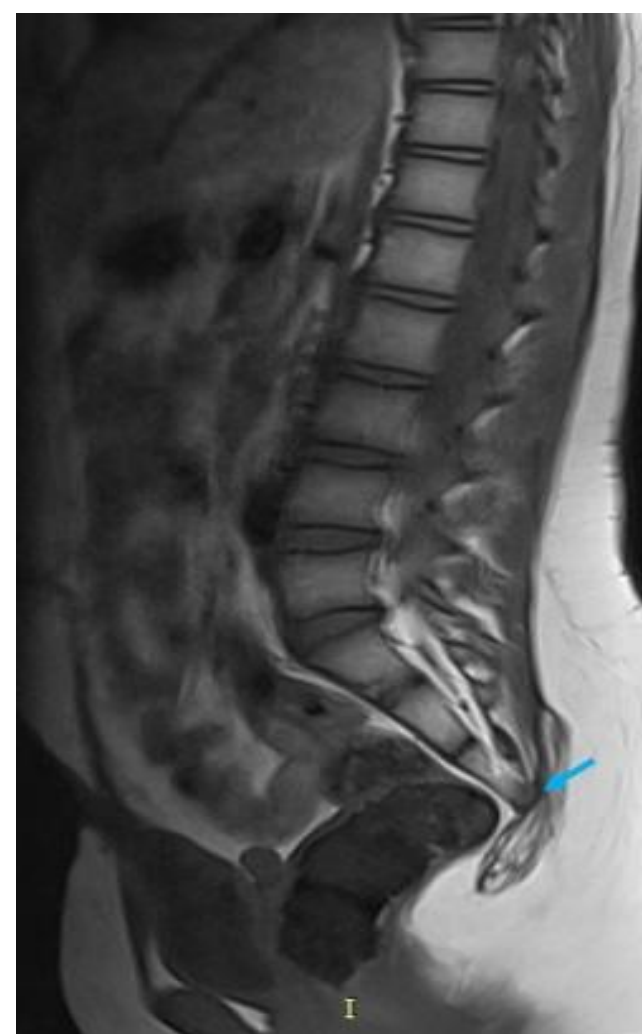

Fig-1a: Lumbar MRI (sagittal T1): Total agenesis of S4, S5 and of the coccyx (arrow)

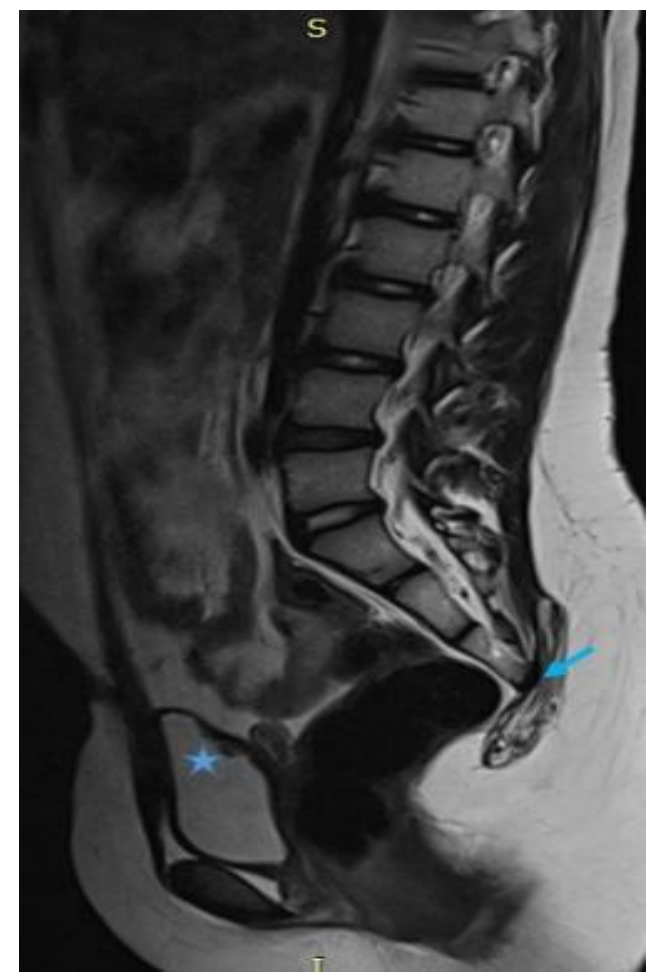

Fig-1b: Lumbar MRI (sagittal T2): Total agenesis of S4, S5 and coccyx (arrow) with diverticular bladder (star)

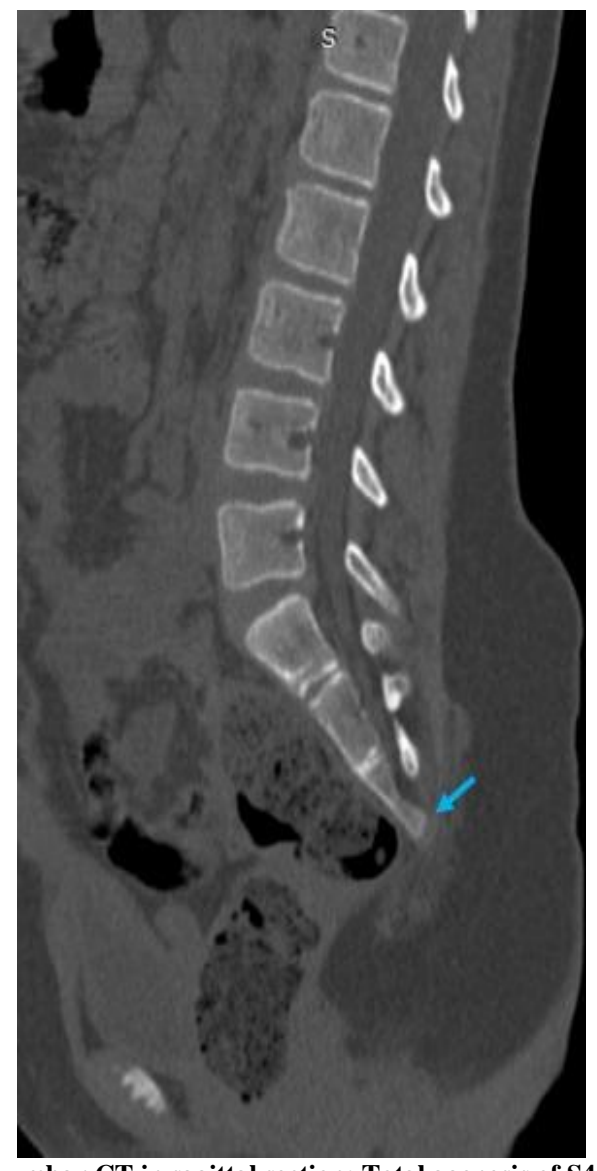

Fig-2: Lumbar CT in sagittal section: Total agenesis of S4, S5 and of the coccyx

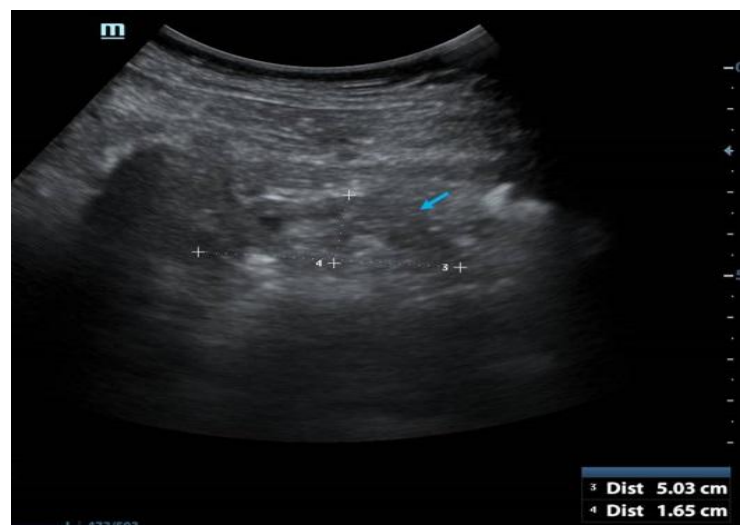

Fig-3a: Abdominal ultrasound: Left kidney reduced in size

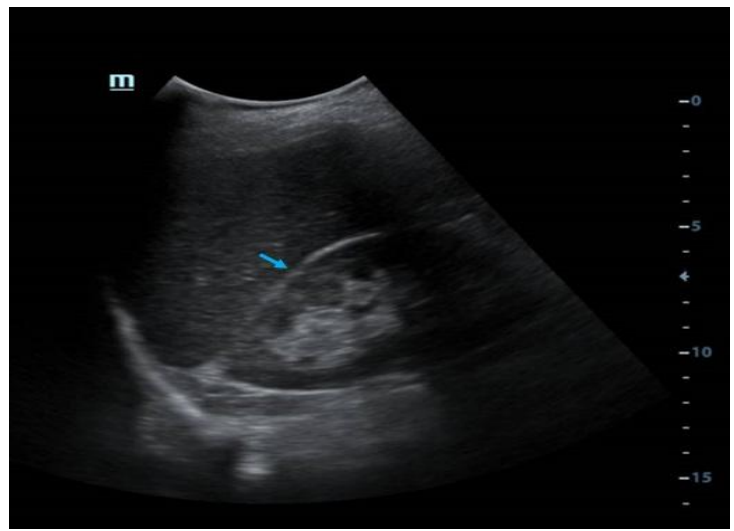

Fig-3b: Abdominal ultrasound: normal right kidney 


\section{Discussion}

Caudal regression syndrome (CRS) is a rare congenital syndrome characterized by agenesis or dysgenesis of vertebrae in the caudal region coexisting with malformations of the spinal cord [3]. Orthopedic, gastrointestinal, genitourinary and cardiac abnormalities are frequently observed in this entity [6]. The sex ratio is $2.7 / 1$ [7]. Caudal regression syndrome is an inadequate term to describe sacral agenesis, in fact there is no regression of the sacrum but, rather, an absence of its development, which is more or less severe. The presence of caudal regression syndrome and neurologic bladder have a relationship with maternal diabetes. The Renshaw classification is useful in distinguishing between different tables of Agenesis of the sacrum [5]. Its clinical manifestations are variable, of which urinary incontinence is the most common symptom [4]. The risk of mortality is extremely low, however recurrent urinary tract infections can sometimes engage the functional and vital prognosis [3, 7]. CRS can cause a neurologic bladder without producing any neurologic symptoms [8]. Indeed, we must think of a caudal regression syndrome in front of any neurological bladder and vice versa.

Imaging plays a key role in diagnosis and treatment decision [3]. The classic findings of prenatal ultrasound are sudden interruption of the spine with absence of low thoracic, lumbar or sacral vertebrae and abnormal lower extremity position or hypoplasia of the lower limbs. First trimester ultrasound signs suggesting the diagnosis include short crown-rump length, protruberance of the lower spine and increased nuchal translucency. The diagnosis can be suspected at 13 weeks' gestation, but is usually not detected until the middle of the second trimester, because the sacrum is not fully ossifed until approximately 18 weeks [9]. Ultrasound can detect associated urinary abnormalities, such as renal agenesis and cystic dysplasias [6]. A standard X-ray of the lumbosacral spine, pelvis, and lower extremities can contribute to the diagnosis. The CT scan confirms the bone abnormalities.

Magnetic resonance imaging (MRI) helps to understand the morphology and pathogeny of the birth defects involved [10]. MRI may be a useful adjunct to US in certain cases of caudal regression especially in obese patients or patients with oligohydramnios. It also can confirm the absence or disorganization of ossification centers and may illustrate cord termination with a wedge-shaped or tapered termination of the cord [9].

Imaging can differentiate two large groups of patients with caudal regression syndrome:

Group 1: Conus medullaris is blunt and ends above the normal level and is sometimes associated with a dilated central canal or cerebrospinal fluid filled cyst with at the lower end of the cone. These patients have major sacral deformities [11].
Group 2: Conus medullaris is elongated and attached by a thickened filum terminale or intraspinal lipoma and ends below the normal level. Neurological disorders are more serious in this group [11].

The management is multidisciplinary made mainly by pediatricians, orthopedists and urologists. Surgery may be necessary to correct or improve symptoms of associated abnormalities [9]. As the case of our patient who underwent a vesicotomy followed by placement of a continent urinary diversion type «Mitrofanoff» which consists of the interposition of the appendix between the bladder and the skin [12]. The goals of treatment include prevention of urinary tract infections, preservation of renal function, achievement of continence, and optimization of motor neurological function [9].

\section{CONCLUSION}

Caudal regression syndrome is revealed by varying symptoms depending on the type of vertebral iliac involvement and associated abnormalities, the main symptom is the neurological bladder. Hence the interest to look for it in front of recurrent urinary tract infections, urinary incontinence or painful urination and to request the appropriate radiological examinations to make the diagnosis including the lumbosacral MRI of the spinal cord, even prenatal diagnosis by ultrasound or fetal MRI, to prevent a delay in diagnosis as in case of our patient, in order to institute an adequate and early management and prevent renal failure.

Declaration of Interests: Authors have no conflict of interest to declare.

\section{REFERENCES}

1. Al Kaissi A, Klaushofer K, Grill F. Caudal regression syndrome and popliteal webbing in connection with maternal diabetes mellitus: a case report and literature review. Cases journal. 2008;1(1):407.

2. Tilfine C, Laamrani FZ., Dafiri R. Syndrome de régression caudale: à propos d'un cas. Pan African Medical Journal. 2018;30(1).

3. Kalicka K, Zajączkowska MM, Piechuta L, Czyż J, Kasza A, Majewski M et al. Neurogenic bladder as a symptom of caudal regression syndrome. Pediatria Polska. 2016;91(6):628-631.

4. Zhang H, Guo H, He S, Hui H, Hao D. Sacral agenesis combined with spinopelvic dissociation: A case report and literature review. Medicine. 2018;97(37).

5. Mottet N, Chaussy Y, Auber F, Guimiot F, ArbezGindre F, Riethmuller D, Cretolle C, Benachi A. How to explore fetal sacral agenesis without open dysraphism: key prenatal imaging and clinical implications. Journal of Ultrasound in Medicine. 2018 Jul;37(7):1807-20.

6. Sen CKK, Patel SLCM. Caudal regression syndrome. Medical Journal Armed Forces India. 2007;63(2):178-179. 
7. Edrees BM. Caudal Regression Syndrome/neurogenic bladder presented as recurrent urinary tract infection. Alexandria Journal of Medicine. 2017;53(3):289-297.

8. Moritoki Y, Kojima Y, Kamisawa H, Mizuno K, Kohri K, Hayashi Y. Neuropathic bladder caused by Caudal Regression Syndrome without any other neurogenic symptoms. Case Reports in medecine. 2012.

9. Heuser CC, Hulinsky RS, Jackson GM. Caudal Regression Syndrome. In Obstetric Imaging: Fetal Diagnosis and Care. Elsevier 2018:291-294.
10. Nievelstein RA, Valk J, Smit LM, Vermeij-Keers C. MR of the caudal regression syndrome: embryologic implications. American journal of neuroradiology. 1994;15(6):1021-1029.

11. Unsinn KM, Geley T, Freund MC, Gassner I. US of the spinal cord in newborns: spectrum of normal findings, variants, congenital anomalies, and acquired diseases. Radiographics. 2000;20(4):923938.

12. Chabchoub K, Fakhfakh H, Sahnoun A, Bahloul A, Mhiri MN. Dérivation urinaire continente de type Mitrofanoff: point de vue de 57 patients. Progrès en urologie (Paris). 2006;16(5):578-583. 